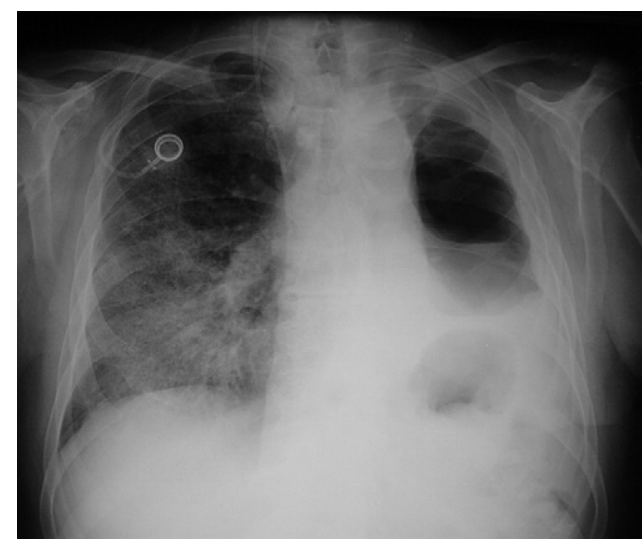

Figure 2. Chest x-ray film of patient 1 showing a left pleural cavity and right pneumopathy.

heart contractions or aortic pulsations, and the risk of opening the contralateral pleura make necessary a clinical study.

We showed the feasibiliy of VAM dissection in resecting the paratracheal mesothelial cysts. ${ }^{2}$ Our cases showed the interest of using VAM for left-sided BPF. The dissection of the trachea through its natural route enables tracheal mobilization. The mediastinal shift is not a contraindication for VAM but represents a risk for contralateral pleural opening during transpericardial sternotomy or the modified Abruzzini technique. ${ }^{4}$ Previous mediastinoscopy is not a contraindication inasmuch as the morbidity is not increased and there is a low risk of contamination. Our 2 cases showed good technical results. The first patient is still alive 2 years after the procedure. Unfortunately, the second patient died of severe sepsis. Perhaps all types of surgery in the presence of severe sepsis are risky.

In conclusion, each patient must be treated individually. The best method of closure must be based on the unique set of circumstances. Direct surgical repair can be achieved in most patients. The VAM technique is our choice for a long (at least $10 \mathrm{~mm}$ ) bronchial stump on the left side because its specific morbidity is minimal compared with transpericardial sternotomy or a transthoracic approach.

\section{References}

1. Asamura H, Naruke T, Tsuchiya R, Goya T, Kondo H, Suemasu K Bronchopleural fistulas associated with lung cancer operations: univariate and multivariate analysis of risk factors, management, and outcome. J Thorac Cardiovasc Surg. 1992;104:1456-64.

2. Pop D, Venissac N, Moroux J. Video-assisted mediastinoscopy: a useful technique for paratracheal mesothelial cysts. J Thorac Cardiovasc Surg. 2005;129:690-1.

3. Azorin JF, Francisci MP, Tremblay B, Larmignat P, Carvaillo D Closure of a postpneumonectomy main bronchus fistula using videoassisted mediastinal surgery. Chest. 1996;109:1097-8.

4. Spaggiari L. Video-assisted Abruzzini technique for bronchopleura fistula repair. A pathology study. J Cardiovasc Surg (Torino). 2000;41: 957-9.

5. Olsen PS, Stentoft P, Ellefsen B, Pettersson G. Re-mediastinoscopy in the assessment of resectability of lung cancer. Eur J Cardiothorac Surg. 1997;11:661-3.

\title{
Gastric conduit staple line after esophagectomy: To oversew or not?
}

Judith Boone, MSc, Inne H. M. Borel Rinkes, MD, PhD, and Richard van Hillegersberg, MD, PhD, Utrecht, The Netherlands

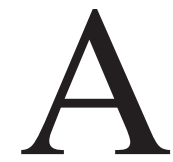

fter esophagectomy, continuity is frequently restored by means of gastric replacement. The staple line of this gastric conduit is generally oversewn to prevent leakage and erosion of adjacent tissue. This last step is often omitted during minimally invasive esophagectomy (MIE)

\footnotetext{
From the Department of Surgery, University Medical Center Utrecht, Utrecht, The Netherlands.

Received for publication July 5, 2006; accepted for publication Aug 8, 2006.

Address for reprints: Richard van Hillegersberg, $\mathrm{MD}, \mathrm{PhD}$, University Medical Center Utrecht, Department of Surgery, G04.228, Heidelberglaan 100, 3584 CX Utrecht, The Netherlands (E-mail: r.vanhillegersberg@ umcutrecht.nl).

J Thorac Cardiovasc Surg 2006;132:1491-2

$0022-5223 / \$ 32.00$

Copyright $\odot 2006$ by The American Association for Thoracic Surgery doi:10.1016/j.jtcvs.2006.08.017
}

because technical difficulties make it time consuming. ${ }^{1}$ Moreover, there is little evidence that supports the need for oversewing staple lines in gastrointestinal surgery. We describe two major complications that occurred after abandoning oversewing the staple line of the gastric conduit after esophagectomy.

\section{Clinical Summary}

PATIENT 1. A 66-year-old woman with a squamous cell carcinoma of the midesophagus underwent robot-assisted thoracoscopic esophagectomy. Through a laparotomy, the resected specimen and abdominal lymph nodes were removed. By using the GIA-stapler (GIA 80, 3.8 mm; Tyco Healthcare, Norwalk, Conn), a 3-cm-wide gastric conduit was created. ${ }^{2}$ The staple line was not oversewn.

On the first postoperative day, the left thoracic drain produced bile. Methylene blue was injected into the nasogastric tube, which was detected in the thoracic drain soon afterward. A contrastenhanced radiographic examination of the gastric conduit showed 
leakage at the distal staple line at the level of the diaphragm (Figure 1).

Relaparotomy revealed a defect of the staple line just above the pylorus. A controlled fistula was made by placing a Foley catheter in the esophageal defect, covering the defect with omentum, and draining the mediastinum. The patient recovered from the mediastinal sepsis after an extended intensive care unit stay of 39 days. On day 45 after the operation, the Foley catheter could be removed. She left the hospital on day 61 in good condition.

PATIENT 2. A 69-year-old man with an adenocarcinoma of the esophagus underwent robot-assisted thoracoscopic esophagectomy with gastric conduit formation through a laparotomy. The staple line was not oversewn.

At day 9, his condition deteriorated, and he had to be reintubated. Because the bronchoalveolar aspirate contained bile, a bronchoscopy was performed, showing a fistula between the right bronchus and the gastric conduit.

Thoracotomy revealed a defect of $4 \mathrm{~cm}$ in the right main bronchus communicating with the neo-esophagus. Given the size of the bronchial defect and the condition of the lung with massive infiltrate, a pneumonectomy was performed. The gastric conduit was well perfused, and the defect was closed with stitches. Despite this intervention, the patient died from ongoing sepsis.

\section{Discussion}

Gastric conduit staple lines are routinely oversewn to prevent local complications. Nevertheless, evidence about the value of this step is scarce. No randomized controlled trials are available comparing complication rates of oversewn versus nonoversewn (gastric) staple lines. In MIE, oversewing the gastric conduit staple line is often omitted because of technical difficulties in laparoscopic suturing. To our knowledge, this is the first report describing the possible consequences of abandoning this step.

In our hospital from 1995 until 2003, 126 consecutive patients underwent esophagectomy for malignancy either through a transthoracic or transhiatal approach. Conduit staple lines were routinely oversewn. No leakage at the staple line has occurred in any of the patients. In contrast, in the first 13 minimally invasive cases, staple lines were not oversewn, resulting in leakage in $2(15 \%)$ patients. ${ }^{2}$ After these 2 events, we reintroduced this step, and no staple line leakage was encountered in the following 20 patients.

The incidence of dehiscent gastrotomy staple lines is not precisely described in the literature. Several factors can contribute to staple line leaks. ${ }^{3}$ Technical inadequacies of stapling material can lead to staple line disruptions, as probably occurred in our first case. ${ }^{3}$ Moreover, surrounding organs can be injured by protruding staples, resulting in fistula, as found in our second case. Third, ischemia in the region of the staple line can cause leakage. Also, staples can be caught in the posterior mediastinum during the conduit pull-up procedure, causing damage to adjacent structures and to the conduit itself. Gastrotomy leaks can lead to severe

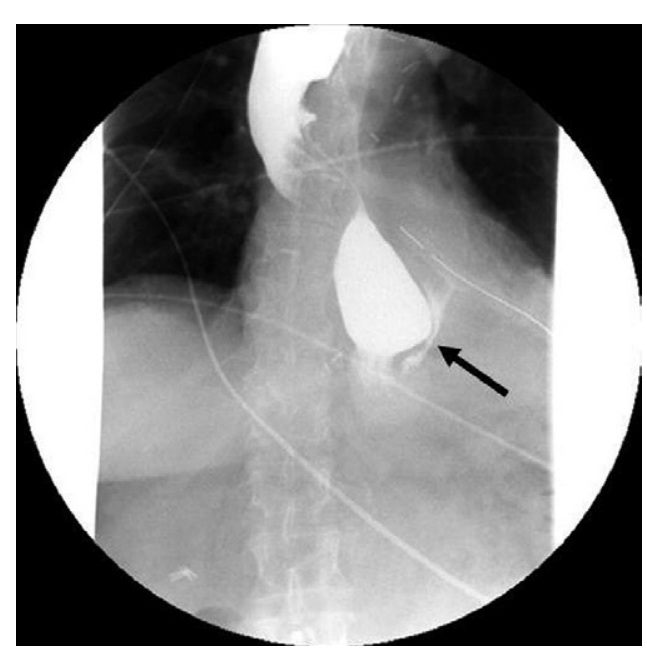

Figure 1. Contrast examination of the neo-esophagus showing leakage (arrow) at the nonoversewn distal staple line in patient 1.

sepsis, mediastinitis, and respiratory-neo-esophageal or aorto-neoesophageal fistulas. ${ }^{4}$

Respiratory neo-esophageal fistula is a rare but dangerous complication of esophagectomy. Although several cases are described of fistulas located at the esophagogastric anastomosis, ${ }^{4}$ few cases are depicted at the staple line of the gastric conduit. ${ }^{4,5}$ In these cases oversewing of the staple line is not reported.

Remarkably, the largest reported series of MIE has not reported any complications at the nonoversewn staple lines in 222 patients. ${ }^{1}$ Nevertheless, because the consequences of a possible leakage are severe and carry a high mortality rate, oversewing the gastric conduit staple line should be performed routinely, even in MIE. In MIE extracorporeally the gastric tube can be created and conventionally oversewn through a $7-\mathrm{cm}$ transverse incision.

\section{References}

1. Luketich JD, Alvelo-Rivera M, Buenaventura PO, Christie NA, McCaughan JS, Litle VR, et al. Minimally invasive esophagectomy: outcomes in 222 patients. Ann Surg. 2003;238:486-94.

2. van Hillegersberg R, Boone J, Draaisma WA, Broeders IAMJ, Giezeman MJMM, Borel Rinkes IHM. First experience with robot-assisted thoracoscopic esophago-lymphadenectomy for esophageal cancer. Surg Endosc. 2006;20:1435-9.

3. Baker RS, Foote J, Kemmeter P, Brady R, Vroegop T, Serveld M. The science of stapling and leaks. Obes Surg. 2004;14:1290-8.

4. Buskens CJ, Hulscher JBF, Fockens P, Obertop H, van Lanschot JJ. Benign tracheo-neo-esophageal fistulas after subtotal esophagectomy. Ann Thorac Surg. 2001;72:221-4.

5. Pramesh CS, Sharma S, Saklani AP, Sanghvi BV. Broncho-gastric fistula complicating transthoracic esophagectomy. Dis Esophagus. 2001; $14: 271-3$ 